\title{
Comparison of Stress Relieving Effects of Horticultural Therapy Programs between Judging and Perceiving Personality Types among Female Undergraduate Students
}

\author{
Su Yeon $\mathrm{An}^{1}$, Jong Won Hong ${ }^{2}$, Eu Jean Jang ${ }^{3}$, and Jongyun Kim ${ }^{4 *}$ \\ ${ }^{1}$ Master student, Department of Horticulture and Biotechnology, Korea University, Seoul 02841, Korea \\ ${ }^{2}$ Research professor, Institute of Life Science and Natural Resources, Korea University, Seoul 02841, Korea \\ ${ }^{3}$ Instructor, Graduate School of Life and Environment Science, Korea University, Seoul 02841, Korea \\ ${ }^{4}$ Associate professor, Department of Plant Biotechnology, Korea University, Seoul 02841, Korea
}

\section{ABSTRACT}

Background and objective: This study was conducted to investigate the effects and preferences of horticultural therapy programs for stress relief according to MBTI personality types (Judging and Perceiving types) of female undergraduate students.

Methods: The participants were divided into 15 Judging and 15 Perceiving types based on lifestyle preferences of the MBTI personality test, and a total of 30 participants participated in the horticultural therapy programs for 6 sessions.

Results: Both Judging and Perceiving types showed a significant decrease in stress after participating in the horticultural therapy programs. Among the 8 life stress subfactors, Judging types showed significant stress relieving effects in 5 subfactors (relationship with the opposite sex, relationship with family, economic problems, future problems, value problems), while Perceiving types showed stress relieving effects in only 3 subfactors (relationship with family, economic problems, future problems). However, the changes in stress relief of 8 subfactors were not significantly different between the two personality types. The most preferred program for the Judging types was 'Making a flower basket', while the most preferred ones for the Perceiving types were 'Planting monstera', and 'Making preserved lemons with marigold', suggesting that the preferences varied depending on personality types.

Conclusion: Therefore, it is necessary to develop suitable horticultural therapy programs for different subjects based on their personality types to enhance the effect of the programs on the subjects.

Keywords: complementary and alternative medicine, horticultural activities, MBTI, program preference, stress relief

\section{Introduction}

Horticultural therapy helps improve or maintain the human mind and body using plants as the medium. Since it was first introduced by the Korean Society for Horticultural Science in 1987 (Kwack, 1984), over 370 articles registered in the Korea Citation Index (KCI) have been published [searched as of October 2020 on Research Information Sharing Service (RISS)] in the 2000s alone, showing that active research has been conducted on horticultural therapy in Korea. Previous studies include those conducted on different age groups such as preschool children, adolescents, college students, and the elderly, as well as those on groups with specific characteristics such as juvenile delinquents, cancer patients, and schizophrenics. Some of them also reported that horticultural therapy programs relieved the stress of participants (Eum and Kim, 2016; Jo, 2013; Kim and Kim, 2009; Lee and Choi, 2012; Lee et al., 2016; Park

Received: July 3, 2020, Revised: July 29, 2020, Accepted: January 7, 2021

First author: Su Yeon An, ahycoolmin@naver.com, (i) https://orcid.org/0000-0002-8547-5640

*Corresponding author. Jongyun Kim, jongkim@korea.ac.kr, (D) https://orcid.org/0000-0001-8085-9592 
and Huh, 2010; Son 2015; Yun and Choi, 2010). Most studies on horticultural therapy applied horticultural therapy programs to the subjects to determine how they changed after the programs, but recent studies are making attempts to verify the programs based on scientific basis to increase the therapeutic effects (Lee et al., 2016) and find factors that have positive or negative effects by analyzing previous studies on horticultural therapy (Jang et al., 2010). These studies lead to participation of psychiatry, rehabilitation medicine, and nursing science majors (Chiang et al., 2006; Eum and Kim, 2016; Kim et al., 2003; Lee et al., 2016), expanding the scope to complementary and alternative medicine.

The Myers-Briggs Type Indicator (MBTI) is a tool based on the theory of psychological types by Swiss psychiatrist, Carl Gustav Jung (1971), developed to find individual dispositions and preferences and determine how they interact and affect human behavior to apply them to real life (Choi, 2016). Four opposite pairs of preferences [Extroversion-Introversion, Sensing-Intuition, Thinking-Feeling, Judging-Perceiving] are used to classify human dispositions and preferences into 16 types (Kim et al., 2015; Park and Kim, 2013), and these personality types are used to study individual and collective development and change (Passmore, 2019). In horticultural therapy, there have been studies classifying college students by the MBTI personality type and examining horticultural programs and preferences for plant types, characteristics, forms of leaves and flowers, fragrances, and colors (Jeong and Huh, 2011) to apply plants and horticultural therapy programs suitable for each subject. However, there are no studies that investigated the stress relieving effect of horticultural therapy programs by personality type (based on the searched results as of October 2020 on RISS).

Since there is difficulty in a simultaneous experiment of 8 personality types according to the preference indicator as it exceeds the capacity, this study decided that Judging and Perceiving, which showed a significant difference in both stress and horticultural preference in previous studies, were suitable for comparison (Jeong and Huh, 2011; Ryu, 1999). Among lifestyle preferences, Judging types have a clear goal and direction, prefer to use time effectively, seek rest or entertainment after finishing their job since they give priority to work, and are methodical (Choi, 2016).
On the other hand, Perceiving types think that goals and directions can be changed and time is an overflowing resource, tend to put off their work willingly if something interesting comes up, and are autonomous and flexible (Choi 2016). Programs considering such different characteristics of MBTI personality types help participants perceive their unique features and understand other people's personalities (Passmore, 2019), thereby showing better therapeutic effect (Lee and Jeoung, 2006), while also enabling personal data collection within a short time (Jeong and No, 2003) for natural approach and rapport building (Bayne 2005). Therefore, as orthodox medicine diagnoses the patient's conditions and prescribes suitable treatment (Kim, 2003), considering the personalities of horticultural therapy participants and carrying out suitable programs can maximize the therapeutic effect. Accordingly, this study was conducted to verify the different stress relieving effects of horticultural therapy programs for undergraduate students between the Judging and Perceiving personalities.

\section{Research Methods}

\section{Subjects and period}

To ensure the ethics and rights of the subjects and increase reliability of research, this study was deliberated by the Institutional Review Board (IRB) on the general research design before recruiting the subjects (IRB NO. KUIRB-2019-0227-01). From September 24 to October 17, 2019, we recruited applicants willing to participate voluntarily in this research among undergraduate students at $\mathrm{K}$ University in Seoul by posting the recruitment notice on the bulletin board and community website. Due to the low percentage of male applicants (5 students), we selected only 40 female undergraduate students as the participants. We informed them of the details of the study and obtained consent for participation before starting the research. Through the basic questionnaire, we limited the subjects to undergraduate students that are not allergic to flowers, have no experience participating in a horticultural therapy program, and have never taken a course related to this study. For pretests, we tested their MBTI personality types (Form M), 
life stress, and interest in horticulture. After the basic survey conducted on a total of 40 adequate applicants, 4 of them were excluded from the program as they were allergic to flowers or had no stress index. Total 6 sessions of horticultural therapy programs were carried out on 36 subjects divided into two subfactors of MBTI personality types, Judging (18 subjects) and Perceiving (18 subjects). However, there was a dropout (1 Judging type) and some absentees (2 Judging types and 3 Perceiving types), which were excluded from the analysis, and the results were derived based on data of total 30 subjects: 15 Judging and 15 Perceiving types. The horticultural therapy programs for stress relief were carried out for 6 weeks from October 30 to December 4, 2019. We repeatedly measured their life stress after the program and had the subjects rate on a 5-point Likert scale their preferences for the 6-session horticultural therapy programs, willingness to participate again, and contribution of the programs to stress relief.

\section{Horticultural therapy programs}

The objective of this study is to determine the life stress relief and program preference of undergraduate students depending on the Judging and Perceiving personality types. To organize suitable horticultural therapy programs, we searched RISS for positive research findings on stress relief of middle school, high school, and undergraduate students from 2010 to 2018, examining master's and doctoral theses and 12 articles published in scientific journals (Bea, 2018; Ha, 2013; Jo, 2013; Kang et al., 2012; Kim, 2010; Lee and Choi, 2012; Lim, 2015; Mun, 2013; Son, 2011; Son et al., 2013; Son, 2015; Yang and Park, 2018), as well as expectations undergraduate students have for horticultural therapy programs. We investigated the frequency and characteristics of horticultural activities based on previous studies (Jung, 2008; Kim, 2007) and classified them into five types of activities such as arts and crafts, growing, learning, cooking, and outdoor activities. We modified and supplemented outdoor activities to indirect outdoor activities using videos due to time constraints and seasonal limitations. Moreover, we organized the programs for those that can intrigue undergraduate students with no experience in horticultural activities and can be easily followed by them. The programs were short-term programs in 6 sessions carried out once a week for 70 minutes each, avoiding the midterm and final seasons. All programs were carried out simultaneously on the Judging and Perceiving subjects to obtain valid results with the same experimental conditions.

The programs were carried out in three stages such as introduction, development, and conclusion in each session. In the introduction stage, the subjects exchanged feedback on their previous session and satisfied their curiosity about plants. In the development stage, visual materials were prepared to smoothly deliver the contents of activities and related knowledge, and the program was carried out according to the detailed goals. The conclusion stage built up the expectations for the next session and induced continuous interest in horticultural activities.

Session 1 was making a flower bouquet that is accessible in everyday life to easily approach and intrigue the subjects that are not familiar with horticulture. In Session 2, the subjects transplanted mini monstera that is easy to grow into a new pot and learned how to take care of it so that they can enhance interest and affection toward the plant they planted. Session 3 was decorating postcard-size drawing paper with pressed flowers, intended to raise concentration and forget the stressors for a moment through the elaborate work. Session 4 was making a flower basket so that the subjects could relieve stress with the simple and interesting act of putting flowers into the floral foam. In Session 5, the subjects watched various garden video clips on indoor and outdoor gardening and relieved stress by making a small garden on the desk with succulent plants and ornaments. Finally, in Session 6, they made preserved lemons with edible flowers and enjoyed floral tea together, stimulating their five senses with the beautiful colors of flowers and fruits, the refreshing and tangy fragrance of lemon, and the sounds of the forest to relieve stress. Each program of the six sessions was aimed at relieving stress of undergraduate students according to MBTI personality types, and the detailed goals and activity types of each session are as follows (Table 1). 
Table 1. Horticultural therapy programs used in the current research

\begin{tabular}{|c|c|c|c|c|}
\hline Session & Program & Purpose & Activity type & Main items \\
\hline 1 & Making a flower bouquet & $\begin{array}{l}\text { To improve interest in horticultural } \\
\text { therapy }\end{array}$ & $\begin{array}{l}\text { Art \& craft activity } \\
\text { Learning activity }\end{array}$ & cut flower, wrapping paper \\
\hline 2 & Planting monstera & $\begin{array}{l}\text { Emotional stability and stress relief } \\
\text { through companion plants }\end{array}$ & $\begin{array}{l}\text { Growing activity } \\
\text { Learning activity }\end{array}$ & mini monstera, pot, soil \\
\hline 3 & Making a pressed flower frame & $\begin{array}{l}\text { To forget stress through } \\
\text { concentration }\end{array}$ & $\begin{array}{l}\text { Art \& craft activity } \\
\text { Learning activity }\end{array}$ & pressed flower, frame \\
\hline 4 & Making a flower basket & $\begin{array}{l}\text { To relieve stress by using fun and } \\
\text { creative activity }\end{array}$ & $\begin{array}{l}\text { Art \& craft activity } \\
\text { Learning activity }\end{array}$ & cut flower, basket, floral foam \\
\hline 5 & $\begin{array}{l}\text { Watching garden video clips } \\
\text { and making mini garden with } \\
\text { succulent plant }\end{array}$ & $\begin{array}{l}\text { To relieve stress through a small } \\
\text { garden on the desk }\end{array}$ & $\begin{array}{l}\text { Outdoor activity } \\
\text { Learning activity } \\
\text { Growing activity }\end{array}$ & $\begin{array}{l}\text { succulent plant, pot, soil, color } \\
\text { sand, ornament, video for indoor } \\
\text { and outdoor gardens }\end{array}$ \\
\hline 6 & $\begin{array}{l}\text { Making preserved lemons with } \\
\text { marigold }\end{array}$ & $\begin{array}{l}\text { To relieve stress by using } \\
\text { five-sensory stimuli }\end{array}$ & $\begin{array}{l}\text { Cooking activity } \\
\text { Learning activity }\end{array}$ & $\begin{array}{l}\text { lemon, dry marigold, sugar, glass } \\
\text { bottle }\end{array}$ \\
\hline
\end{tabular}

\section{Measurement tools}

\section{MBTI personality test}

The MBTI personality test used in this study to determine the personality types of participants was the Korea Institute of Psychological Aptitude Test's MBTI self-scorable (Form M). The test determines individual dispositions and preferences, comprising of total 93 items for the participants to choose the answer that is often closest to their behavior (Choi, 2016). Based on the results of this test, we divided the subjects that are Judging and Perceiving types out of four preferences into two groups with 15 subjects in each group. Moreover, considering that the subjects' awareness of their personality types may affect their stress and preference measurement, the test results were disclosed after all the programs were over.

\section{Stress scale}

To measure the stress levels of undergraduate students, we adopted the questionnaire by Kim and Chung (2019) who revised and supplemented the revised questionnaire in the study developing the life stress scale for undergraduate students (Chon et al., 2000) and rated their life stress on a 5-point Likert scale with total 50 items. We divided the life scale of undergraduate students into subfactors of interpersonal relations and pending problems, examining total 8 subdomains such as relationships with the opposite sex, friends, family, and professors for inter- personal relationships, and academic, economic, future, and value problems for pending problems. The participants were to rate each item as 'Never' (1 point), 'Rarely' ( 2 points), 'Occasionally' (3 points), 'Frequently' (4 points), and 'Very Frequently' (5 points), with higher scores indicating a higher level of stress. The reliability of the previous study (Kim and Chung, 2019) was Cronbach $\alpha=0.95$, and that of this study was Cronbach $\alpha=.905$, confirming a high level of reliability.

\section{Preferences for horticultural therapy programs}

To determine the preferences of the Judging and Perceiving types for horticultural therapy programs, we rated their preferences for the programs in each session on a 5-point Likert scale after the programs and compared the preferences and order of preference for each program depending on personality type.

\section{Data analysis method}

The survey results were digitized and statistically analyzed using IBM SPSS Statistics 25. To test the homogeneity of the Judging and Perceiving types, we conducted an independent samples t-test between the groups on interest in horticulture and stress scale before the programs. We also conducted a paired t-test to determine the stress relieving effect of horticultural therapy programs before and after depending on personality type. Moreover, two-way 
ANOVA was conducted with personality type and programs as the factors to determine the preferences for horticultural therapy programs depending on personality type, and the Scheffé's test was used for the post-hoc test. All statistics were tested at the 95\% confidence level (or 5\% significance level).

\section{Results and Discussion}

\section{General characteristics of the subjects and homogeneity}

The subjects of this study were 30 female undergraduate students attending K University divided by lifestyle preferences into Judging types (15 subjects) and Perceiving types (15 subjects). The majors, divided into liberal arts and sciences, showed a similar distribution of the two personality types (Table 2). The homogeneity test conducted on interest in horticulture and life stress scale of the subjects before the programs showed that interest in horticulture $(\mathrm{M}=$ 4.20) of the Judging types was higher than preference (M $=3.86$ ) of the Perceiving types, but there was no statistically significant difference ( $p=.176$, Table 3 ). Also in the life stress scale measured in the process of recruiting the subjects, there was no difference between the Judging types $(\mathrm{M}=2.62)$ and Perceiving types $(\mathrm{M}=2.41)(p=$ .266), and also no difference between the two groups in interest in horticulture and stress before the programs (Table 3).

\section{Life stress scale}

We conducted the pretest and posttest to determine the stress relieving effect of the programs for undergraduate students that have Judging and Perceiving personalities, and the results showed that life stress decreased in both groups after the programs (Judging $p=.004$, Perceiving $p=.002$, Table 4). This is similar to the results of previous studies in which negative emotions changed into positive emotions after carrying out horticultural therapy programs on undergraduate students (Jo, 2013; Yang and Park, 2018), and middle and high school students (Bea, 2018; Ha, 2013; Kang et al., 2012; Kim, 2010; Lee and Choi, 2012; Lim, 2015; Mun, 2013; Son, 2011; Son et al., 2013; Son, 2015). However, the stress relieving effect did not show a significant difference between Judging and Perceiving personality types $(p=.781$, Table 4$)$. Therefore, regardless of

Table 2. Characteristics of the subjects

\begin{tabular}{|c|c|c|c|c|c|c|c|c|}
\hline \multirow[t]{2}{*}{$\begin{array}{l}\text { Group } \\
\%(n)\end{array}$} & \multicolumn{2}{|c|}{$\begin{array}{c}\text { Major course } \\
\%(n)\end{array}$} & \multicolumn{2}{|c|}{$\begin{array}{c}\text { Flower allergy } \\
\%(n)\end{array}$} & \multicolumn{2}{|c|}{$\begin{array}{c}\text { Experience of horticultural } \\
\text { therapy program } \\
\%(\mathrm{n})\end{array}$} & \multicolumn{2}{|c|}{$\begin{array}{c}\text { Taking course for } \\
\text { horticulture therapy } \\
\%(n)\end{array}$} \\
\hline & Liberal arts & Science & Yes & No & Yes & No & Yes & No \\
\hline $\begin{array}{c}\text { Judging } \\
50(15)\end{array}$ & $73(11)$ & $27(4)$ & $0(0)$ & $100(15)$ & $0(0)$ & $100(15)$ & $0(0)$ & $100(15)$ \\
\hline $\begin{array}{l}\text { Perceiving } \\
50(15)\end{array}$ & $67(10)$ & $33(5)$ & $0(0)$ & $100(15)$ & $0(0)$ & $100(15)$ & $0(0)$ & $100(15)$ \\
\hline Total & & & & & & & & $100(30)$ \\
\hline
\end{tabular}

Table 3. Pre-homogeneity test of subjects

\begin{tabular}{|c|c|c|c|c|c|}
\hline Category & Personality type & $\mathrm{N}$ & Mean (SD) & $\mathrm{t}$ & $p$ \\
\hline \multirow{2}{*}{ Interest in horticulture } & Judging & 15 & $4.20(0.56)$ & \multirow{2}{*}{1.387} & \multirow{2}{*}{$.176^{\mathrm{NS}}$} \\
\hline & Perceiving & 15 & $3.86(0.74)$ & & \\
\hline \multirow{2}{*}{ Pre-stress scale } & Judging & 15 & $2.62(0.54)$ & \multirow{2}{*}{1.136} & \multirow{2}{*}{$.266^{\mathrm{Ns}}$} \\
\hline & Perceiving & 15 & $2.41(0.46)$ & & \\
\hline
\end{tabular}

Normalized Likert 5 scale of each category, ${ }^{\text {NS }}$ Non-significant by t-test. 
the MBTI personality type, there was stress relieving effect on female undergraduate students after participating in the horticultural therapy programs.

As a result of comparing the means of the subfactors of Judging and Perceiving personality types, it was found that both personality types suffered greater stress from pending problems (academic, economic, future, value problems) than interpersonal relationships (relationship with the opposite sex, friends, family, and professors) (Table 5). This is similar to the results of the study by Bak and Kang (2012) proving that undergraduate students suffer greater stress from pending problems than interpersonal relationships.

As a result of comparing the difference in the stress relieving effect on interpersonal relationships and pending problems before and after the programs, it was found that the Judging types showed a similar decrease in interpersonal relationships $\left(\mathrm{M}_{\mathrm{dif}}=-0.48\right)$ and pending problems $\left(\mathrm{M}_{\text {dif }}=-0.40\right)$, and so did the Perceiving types (interpersonal relationships $\mathrm{M}_{\mathrm{dif}}=-0.40$, pending problems $\mathrm{M}_{\mathrm{dif}}=-0.37$ ).
Both types showed the stress relieving effect after participating in the programs, but there was no difference in the stress relieving effect depending on the personality type (Table 5). Therefore, horticultural therapy programs helped relieve female undergraduate students' stress from interpersonal relationships and pending problems regardless of whether they are Judging or Perceiving types. As they start their social life as adults and begin learning, undergraduate students need to find ways to positively cope with stress they encounter in everyday life, and horticultural therapy may be a suitable way to contribute to the stress relief of undergraduate students.

As a result of examining which factors show the stress relieving effect in the two personality types by classifying the life stress scale of undergraduate students into 8 subfactors (relationship with the opposite sex, relationship with friends, relationship with family, relationship with professors, academic problems, economic problems, future problems, value problems), the Judging and Perceiving types did not

Table 4. Pre-post difference test of life stress scale by personality types of university students

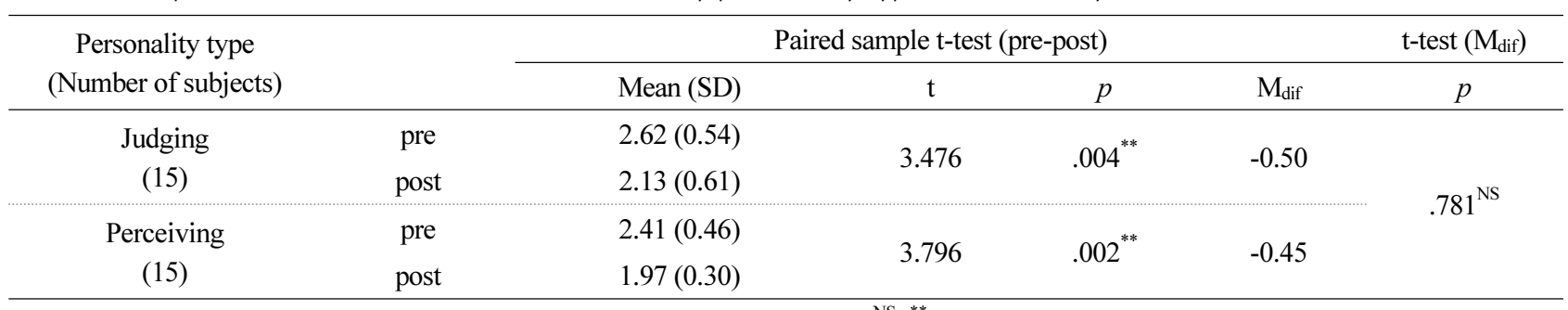

Normalized Likert 5 scale of 50 questionnaires, $\mathrm{M}_{\mathrm{dif}}=$ post mean - pre mean, ${ }^{\mathrm{NS}},{ }^{* *}$ Non-significant or significant at $p<.01$ by t-test.

Table 5. Comparison of the sub-factors (interpersonal relationship, pending problem) of life stress scale by personality types

\begin{tabular}{|c|c|c|c|c|c|c|c|}
\hline \multirow{2}{*}{ Category } & \multirow{2}{*}{$\begin{array}{c}\text { Personality type } \\
\text { (Number of subjects) }\end{array}$} & & \multicolumn{4}{|c|}{ Paired sample t-test (pre-post) } & \multirow{2}{*}{$\frac{\mathrm{t} \text {-test }\left(\mathrm{M}_{\mathrm{dif}}\right)}{p}$} \\
\hline & & & Mean (SD) & $\mathrm{t}$ & $p$ & $M_{\text {dif }}$ & \\
\hline \multirow{4}{*}{$\begin{array}{l}\text { Interpersonal } \\
\text { relationship }\end{array}$} & Judging & pre & $2.08(0.85)$ & 2507 & $021^{*}$ & & \multirow{4}{*}{$0.754^{\mathrm{NS}}$} \\
\hline & $(15)$ & post & $1.60(0.76)$ & 2.592 & .021 & -0.48 & \\
\hline & Perceiving & pre & $1.89(0.63)$ & \multirow{2}{*}{2.935} & \multirow{2}{*}{$.011^{*}$} & \multirow{2}{*}{-0.40} & \\
\hline & (15) & post & $1.49(0.41)$ & & & & \\
\hline \multirow{4}{*}{$\begin{array}{l}\text { Pending } \\
\text { problem }\end{array}$} & Judging & pre & $3.04(0.65)$ & 2356 & $034^{*}$ & & \multirow{4}{*}{$0.868^{\mathrm{NS}}$} \\
\hline & $(15)$ & post & $2.63(0.68)$ & 2.356 & .034 & -0.40 & \\
\hline & Perceiving & pre & $2.81(0.41)$ & \multirow{2}{*}{3.220} & \multirow{2}{*}{$.006^{* *}$} & \multirow{2}{*}{-0.37} & \\
\hline & (15) & post & $2.44(0.32)$ & & & & \\
\hline Total & 30 & & & & & & \\
\hline
\end{tabular}

Likert 5 scale, $\mathrm{M}_{\mathrm{dif}}=$ post mean - pre mean, ${ }^{\mathrm{NS}},{ }^{*},{ }^{* *}$ Non-significant or significant at $p<.05, p<.01$ by t-test. 
show a difference in the extent of stress relief in the 8 subfactors (Table 6). However, comparison of the results in each subfactor before and after the programs showed that there was a difference in the efficacy of stress relief depending on personality type. Out of 8 factors, the Judging types showed the stress relieving effect in 5 factors (relationship with the opposite sex, relationship with fam- ily, economic problems, future problems, value problems), while the Perceiving types showed the stress relieving effect in 3 factors (relationship with family, economic problems, value problems).

According to a previous study (Jo, 2006), personality traits influence how to cope with stress, as the Judging types mostly used wishful thinking, followed by prob-

Table 6. Pre- and post-tests of life stress scales of university students by stress factors according to personality types

\begin{tabular}{|c|c|c|c|c|c|c|c|}
\hline \multirow{2}{*}{ Stress factor } & \multirow{2}{*}{$\begin{array}{c}\text { Personality type } \\
\text { (Number of subjects) }\end{array}$} & & \multicolumn{4}{|c|}{ Paired sample t-test (pre-post) } & \multirow{2}{*}{$\frac{\mathrm{t} \text {-test }\left(\mathrm{M}_{\mathrm{dif}}\right)}{p}$} \\
\hline & & & Mean (SD) & $\mathrm{t}$ & $p$ & $\mathrm{M}_{\text {dif }}$ & \\
\hline \multirow{4}{*}{$\begin{array}{l}\text { Relationship } \\
\text { with opposite } \\
\text { sex }\end{array}$} & Judging & pre & $2.51(1.42)$ & 2620 & $020^{*}$ & 006 & \multirow{4}{*}{$0.167^{\mathrm{NS}}$} \\
\hline & (15) & post & $1.56(0.93)$ & 2.029 & $.0 \angle 0$ & -0.90 & \\
\hline & Perceiving & pre & $1.74(0.95)$ & & $123^{\mathrm{NS}}$ & & \\
\hline & (15) & post & $1.39(0.38)$ & 1.639 & .123 & -0.36 & \\
\hline \multirow{4}{*}{$\begin{array}{l}\text { Relationship } \\
\text { with friends }\end{array}$} & Judging & pre & $2.13(0.79)$ & 2017 & $063^{\mathrm{NS}}$ & ת 02 & \multirow{4}{*}{$0.799^{\mathrm{NS}}$} \\
\hline & $(15)$ & post & $2.33(0.85)$ & 2.011 & & -0.20 & \\
\hline & Perceiving & pre & $1.95(0.67)$ & 1348 & $205^{\mathrm{NS}}$ & 027 & \\
\hline & $(15)$ & post & $1.68(0.46)$ & 1.340 & .203 & -0.21 & \\
\hline \multirow{4}{*}{$\begin{array}{l}\text { Relationship } \\
\text { with family }\end{array}$} & Judging & pre & $1.94(0.91)$ & 2390 & $031^{*}$ & -041 & \multirow{4}{*}{$0.403^{\mathrm{NS}}$} \\
\hline & (15) & post & $1.53(0.88)$ & 2.390 & .051 & -0.41 & \\
\hline & Perceiving & pre & $2.11(0.64)$ & 4933 & $<001^{* * *}$ & 050 & \\
\hline & (15) & post & $1.52(0.65)$ & 4.933 & $<.001$ & -0.59 & \\
\hline \multirow{4}{*}{$\begin{array}{l}\text { Relationship } \\
\text { with professor }\end{array}$} & Judging & pre & $2.10(1.03)$ & 1380 & $189^{\mathrm{NS}}$ & 036 & \multirow{4}{*}{$0.894^{\mathrm{NS}}$} \\
\hline & (15) & post & $1.74(0.76)$ & 1.500 & & -0.50 & \\
\hline & Perceiving & pre & $2.04(0.86)$ & 1.916 & $.076^{\mathrm{NS}}$ & -0.40 & \\
\hline & $(15)$ & post & $1.64(0.68)$ & & & & \\
\hline \multirow{4}{*}{$\begin{array}{l}\text { Academic } \\
\text { problem }\end{array}$} & Judging & pre & $3.07(0.76)$ & -0.287 & $778^{\mathrm{NS}}$ & +0.07 & \multirow{4}{*}{$0.240^{\mathrm{NS}}$} \\
\hline & $(15)$ & post & $3.13(0.79)$ & & & & \\
\hline & Perceiving & pre & $2.91(0.70)$ & 1648 & $122^{\mathrm{NS}}$ & -028 & \\
\hline & (15) & post & $2.64(0.71)$ & & & & \\
\hline \multirow{4}{*}{$\begin{array}{l}\text { Economic } \\
\text { problem }\end{array}$} & Judging & pre & $2.61(1.13)$ & 2408 & $030^{*}$ & -043 & \multirow{4}{*}{$0.930^{\mathrm{NS}}$} \\
\hline & $(15)$ & post & $2.18(0.86)$ & 2.400 & & -0.43 & \\
\hline & Perceiving & pre & $2.05(0.78)$ & 3761 & $002^{* *}$ & 045 & \\
\hline & $(15)$ & post & $1.60(0.54)$ & 5.101 & & -0.45 & \\
\hline \multirow{4}{*}{$\begin{array}{c}\text { Future } \\
\text { problem }\end{array}$} & Judging & pre & $3.30(0.98)$ & 2815 & $014^{*}$ & -0.61 & \multirow{4}{*}{$0.147^{\mathrm{NS}}$} \\
\hline & $(15)$ & post & $2.69(0.88)$ & 2.015 & .014 & -0.01 & \\
\hline & Perceiving & pre & $3.15(0.51)$ & 1.187 & $255^{\mathrm{NS}}$ & -020 & \\
\hline & $(15)$ & post & $2.95(0.41)$ & & & -0.20 & \\
\hline \multirow{4}{*}{$\begin{array}{l}\text { Value } \\
\text { problem }\end{array}$} & Judging & pre & $3.19(0.82)$ & 2.168 & $048^{*}$ & -0.71 & \multirow{4}{*}{$0.922^{\mathrm{NS}}$} \\
\hline & $(15)$ & post & $2.48(1.09)$ & & & & \\
\hline & Perceiving & pre & $3.20(0.88)$ & 2.764 & $.015^{*}$ & -0.67 & \\
\hline & $(15)$ & post & $2.53(0.70)$ & & & & \\
\hline
\end{tabular}

Likert 5 scale, $\mathrm{M}_{\mathrm{dif}}=$ post mean - pre mean, ${ }^{\mathrm{NS}},{ }^{*},{ }^{* *},{ }^{* * *}$ Non-significant or significant at $p<.05, p<.01, p<.001$ by t-test. 
lem-focused, social support, and emotion-focused, whereas the Perceiving types used mostly used wishful thinking, followed by emotion-focused, problem-focused, and social support. Moreover, the Judging types preferred problem-focused coping strategies more to face and change the stressors than the Perceiving types. This shows that the Judging types with active attitude in which they change the source of stress and request help from others (Oh, 2015) ended up showing the stress relieving effect in more factors than the Perceiving types.

\section{Preferences for horticultural therapy programs}

As a result of conducting two-way ANOVA with personality types and programs as the two factors, it was found that the Judging types showed a generally higher preference for each program than the Perceiving types $(p<.001)$, indicating that the Judging types had a more positive awareness of the programs than the Perceiving types (Table 7).

The order of preferences of the Judging types for horticultural therapy programs was: 1. Making a flower basket, 2. Making preserved lemons with marigold, 3. Making a flower bouquet, 4. Planting monstera, 5. Watching indoor/ outdoor garden video clips and planting succulent plants, and 6. Making a pressed flower frame. Making a flower basket $(\mathrm{M}=4.90)$, in which the process of arranging flow- ers was explained in order with a brief demonstration, was highly preferred by the Judging types who like planned and systematic progress (Choi, 2016). Making a pressed flower frame, in which the subjects freely carried out creative activities without a specific design example, was least preferred among the six programs $(\mathrm{M}=4.20)$.

Unlike the order of preferences of the Judging types, that of the Perceiving types was: 1. Planting monstera, 2. Making preserved lemons with marigold, 3. Making a flower bouquet, 4. Making a pressed flower frame, 5. Watching indoor/outdoor garden video clips and planting succulent plants, and 6. Making a flower basket. Planting monstera $(\mathrm{M}=4.33)$ and making preserved lemons with marigold $(\mathrm{M}=4.33)$, which were relatively simple and easy compared to other programs, showed the highest preference among the Perceiving types, which is similar to the general disposition of this personality type that prefers a relaxed and easygoing process (Choi, 2016). In particular, making a flower basket was the program with the highest preference among the Judging types, but it showed the lowest preference among the Perceiving types, showing a difference in preferences depending on personality type. According to a previous study on the preferences for forest therapy programs depending on personality type such as Judging and Perceiving (Kim et al., 2015), the Judging types preferred orderly and systematic programs (writing in the for-

Table 7. Horticultural therapy programs preference according to the judging and perceiving personality types

\begin{tabular}{|c|c|c|c|c|}
\hline \multirow[b]{3}{*}{ Program } & \multicolumn{4}{|c|}{ Personality type (Number of subjects) } \\
\hline & \multicolumn{2}{|c|}{ Judging (15) } & \multicolumn{2}{|c|}{ Perceiving (15) } \\
\hline & $\begin{array}{l}\text { Program } \\
\text { preference } \\
\text { (SD) }\end{array}$ & Rank & $\begin{array}{l}\text { Program } \\
\text { preference } \\
\text { (SD) }\end{array}$ & Rank \\
\hline Making a flower basket & $4.90(0.25)^{\mathrm{a}}$ & 1 & $3.93(0.79)^{\mathrm{c}}$ & 6 \\
\hline Making preserved lemons with marigold & $4.47(0.45)^{\mathrm{ab}}$ & 2 & $4.33(0.72)^{\mathrm{bc}}$ & 1 \\
\hline Making a flower bouquet & $4.60(0.91)^{\mathrm{ab}}$ & 3 & $4.26(0.88)^{\mathrm{bc}}$ & 3 \\
\hline Planting monstera & $4.40(0.82)^{\mathrm{abc}}$ & 4 & $4.33(0.48)^{b c}$ & 1 \\
\hline Watching garden video clips and making mini garden with succulent plant & $4.33(0.81)^{\mathrm{bc}}$ & 5 & $3.97(0.88)^{\mathrm{c}}$ & 5 \\
\hline Making a pressed flower frame & $4.20(0.86)^{\mathrm{bc}}$ & 6 & $4.00(1.25)^{\mathrm{c}}$ & 4 \\
\hline Program & & & $P<.001^{* * *}$ & \\
\hline Personality type & & & $P=.295^{\mathrm{NS}}$ & \\
\hline Program x Personality type & & & $P=.311^{\mathrm{NS}}$ & \\
\hline
\end{tabular}

Likert 5 scale, ${ }^{* * *},{ }^{N S}$ Non-significant or significant at $p<.001$ by t-test. Means with the same letter are not significantly different by pair-wise comparison at $p<.05$. 
est, listening to forest interpretation, observing plants, horticultural therapy in the forest, etc.), whereas the Perceiving types preferred programs to relax freely (walking barefoot in the forest, aromatherapy massage, forest bathing, camping, etc.), indicating that the preferred programs varied depending on personality type. Moreover, a study comparing the preferences of elementary school students for mathematics teaching methods (Sim, 2014) also showed that there was a difference in preferences depending on personality type for independent learning (learning method carried out by choosing one's own topic), project learning (learning method through group activities or assignments) and debating (learning method in which there is a teacher-student or student-student debate). The Perceiving types relatively preferred the teaching method in which they can participate freely more than the Judging types. As for plants that can be the main material of horticultural therapy, there was a previous study on horticultural preferences of undergraduate students depending on personality type (Jeong and Huh, 2011), which reported that the form of preferred flowers was different between the Judging and Perceiving types. This suggests that it is necessary to develop customized horticultural therapy programs to increase interest and effect by determining the personality types of the subjects and using suitable materials and programs for each personality type.

\section{Conclusion}

This study divided the MBTI personality types into Judging and Perceiving and carried out horticultural therapy programs on female undergraduate students and did not find a difference in the stress relieving effect depending on personality type through the life stress scale, but could find a difference between before and after the programs in both groups. Moreover, in the 8 subfactors of the life stress scale (relationship with the opposite sex, relationship with friends, relationship with family, relationship with professors, academic problems, economic problems, future problems, value problems), the Judging types showed positive effects on 5 subfactors (relationship with the opposite sex, relationship with family, future problems, economic problems, value problems), and the Perceiving types on 3 subfactors (relationship with family, economic problems, value problems), thereby proving the difference between the two types. In other words, the Judging types, who prefer supportive and active problem-solving stress coping strategies, showed the stress relieving effect in more factors than the Perceiving types.

The order of preferences for horticultural therapy programs varied between the two types. In particular, making a flower basket was the most preferred program among the Judging types but the least preferred among the Perceiving types, proving the difference in preferred programs between the two personality types. However, this study has limitations in that it was conducted only on female undergraduate students and unsuccessful to distinguish the different effects of horticultural therapy programs depending on personality type. Thus, there is a need for additional research that supplemented the sample size and program sessions, as well as research that considered the gender ratio or examined male students.

\section{References}

Bak, Y.G and I.S. Kang. 2012. University students of campus life stress, self-esteem and health promotion behavior. Korean J. Health Serv. Manag. 6(4):177-189. https://doi. org/10.12811/kshsm.2012.6.4.177

Bayne, R. 2005. Ideas and evidence: critical reflections on MBTI theory and practice. CAPT, Gainesville, Florida, United states of America: Center for applications of psychological type Publishing.

Bea, W.R. 2018. The effects of free semester horticultural activity program on stress and school life satisfaction. Master's thesis, Korea University, Seoul, Korea.

Chiang, M.H., S.K. Kim, and M.H. Kang. 2006. The preliminary study of psychological-horticultural therapy program for promoting emotional intelligence. $\mathrm{J}$. Psychother. 7(1):1-14.

Choi, J.Y. 2016. Understanding of psychological examination, MBTI (pp. 127-150). Seoul, Korea: Sigmapress Publishing.

Chon, K.K., K.H. Kim, and J.S. Yi. 2000. Development 
of the revised life stress scale for college students. Korean J. Health Psychol. 5(2):316-335.

Eum, E.Y and H.S. Kim. 2016. Effects of a horticultural therapy program on self-efficacy, stress response, and psychiatric symptoms in patients with schizophrenia. J. Korean Acad. Psychiatr. Meantal Health Nurs. 25(1):48-57. https://doi.org/ 10.12934/jkpmhn.2016.25.1.48

Ha,Ha, Y.N. 2013. Effect of horticultural therapy on the psychological well-being and mental health of the girl's high school students. Master's thesis, Korea University, Seoul, Korea.

Jang, E.J., G.W. Han, J.W. Hong, S.E. Yoon, and C.H. Pak. 2010. Meta-analysis of research papers on horticultural therapy program effect. Korean J. Soc. Hortic. Sci. Technol. 28(4):701-707.

Jeong, M and A.Y. No. 2003. The relationship of lifestyle, type theory (MBTI) and life stress. Korean J. Couns. Psychother. 15(4):693-710.

Jeong, S.H and M.R. Huh. 2011. Study on the preferences of horticulture according to MBTI personality type in college students. J. Aric. Life Sci. 45(6):65-72.

Jo, H.J. 2013. Effect of horticultural therapy program using the floral design on the ego-identity, personal relations, and stress of the university students. Master's thesis, Korea University, Seoul, Korea.

Jo, H.H. 2006. Correlation of personality types and coping styles in high school students. Master's thesis, Hannam University, Dajeon, Korea.

Jung, C.G. 1971. Psychological types. New jersey, United States: Princeton university press Publishing.

Jung, S.J. 2008. Analysis of horticultural therapy program for the youth. Master's thesis, Korea University, Seoul, Korea.

Kang, S.U., E.U. Jang, and C.H. Pak. 2012. Effects of horticultural therapy on the self-esteem, social-supporter and stress of the high school students. J. Korean Soc. People Plants Environ. 15(1):9-14.

Kim, L. 2003. Pharmacological treatment of sleep disorders in elderly. J. Korean Geriatr. Psychiatry. 7(1):11-22.

Kim, K.J and N.W. Chung. 2019. Relationship among life stress, depression, and suicidal ideation of university students: moderated mediating effect of self-compassion. Korean J. Health Psychol. 24(1):249-271.
Kim, R.B and H.Y. Kim. 2009. Effect of horticultural therapy on stress and stress coping strategy of juvenile delinquents. J. Korean Soc. People Plants Environ. 12(3):17-23.

Kim, S.M. 2010. (The)effect of horticultural theraphy on stress and mental health for the middle school students. Master's thesis, Korea University, Seoul, Korea.

Kim, S.Y., K.C. Son, H.J. Jung, J.H. Yoo, B.S. Kim, and S.W. Park. 2003. Effect of horticultural therapy on functional rehabilitation in hemiplegic patients after stroke. J. Korean Soc. Hortic. Sci. 44(5):780-785.

Kim, Y.H., D.J. Kim, E.J. Kim, P.S. Yeoun, B.J. Chou, J.K. Kim, and Y.S. Kim. 2015. The preference analysis of forest therapy program with regard to MBTI personality types $^{1 \mathrm{a}}$. Korean J. Environ. Ecol. 29(3):485-498. https://doi.org/10.13047/KJEE.2015.29.3.485

Kim, Y.N. 2007. Analysis of horticultural therapy program for the elderly. Master's thesis, Korea University, Seoul, Korea.

Kwack, B.W. 1984. Newly developing field of horticulture and horticultural science. J. Korean Soc. Hortic. Sci. 2(1):4-8.

Lee, M.J and B.J. Choi. 2012. Effect of horticultural activities on self-esteem and academic stress of the youth. J. Korean Soc. People Plants Environ. 15(2):93-98.

Lee, S.B and M.S. Jeoung. 2006. The effect of parent education program based on the MBTI for mothers' on their parenting self-efficacy, family cohesion and family adaptability. Fam. Environ. Res. 44(10):121-132.

Lee, S.M., Y.H. Choi, G.H. Gim, S.H. Jeong, M.S. Chun, and S. Lee. 2016. Effects of horticultural therapy program based on 'relaxation-social support-cognitive behavior' strategy on quality of life, stress and serotonin of woman cancer patients- focused on indoor activities. J. Korean Soc. People Plants Environ. 19(4):277-284. https://doi.org/10.11628/ksppe.2016.19.4.277

Lim, M.J. 2015. Horticultural activity program for improving school happiness for students in

the department of agriculture in a specialized high school. Master's thesis, Konkuk University, Seoul, Korea.

Horticultural Activity Program for Improving School Happiness for Students in the Department of Agriculture in a Specialized High School 
Mun, Y.J. 2013. Effect of horticultural activities program on the stress, self-esteem and quality of life in a high school students. Master's thesis, Dankook University, Seoul, Korea.

Oh, S.H. 2015. Stress levels and stress coping strategies depending on MBTI personality types of auxiliary policemen. Master's thesis, Jeju National University, Jeju, Korea.

Park, J.H. and B.C. Kim. 2013. The research about change of ISTJ \& ENFP type which is in MBTI personality type indicator in art therapy-by product \& behavior from the program as subject. Korean J. Arts Ther. 13(2):1-29.

Park, S.H and M.R. Huh. 2010. Effects of a horticultural program on the preschool children's emotional intelligence and daily stress. Korean J. Hortic. Sci. Technol. 28(1):114-149.

Passmore, J. 2019. Psychometrics in coaching. Seoul, Korea: Bookherb Publishing.

Ryu, J.Y. 1999. Stress perception, coping and personality type. Psychological Type Hum. Dev. 6(1):107-120.
Sim, M.B. 2014. The comparison of elementary school general students, and mathematics gifted, and science gifted in character style and preference of instructional methods. Master's thesis, Soonchunhyang University, Chungcheongnam-do, Korea.

Son, H.Y. 2011. Effects of horticultural activities on stress and academic motivation of middle school male students. Master's thesis, Catholic University of Daegu, Deagu, Korea.

Son, M.R. 2015. Effect of horticultural therapy on school life adaptation and stress of juvenile. Doctoral dissertation, Wonkwang University, Iksan, Korea.

Yang, K.M. and H.J. Park. 2018. The effect of horticultural activities program on emotional intelligence and stress coping in nursing college student. J. Korea Converge. Soc. 9(2):267-276. http://dx.doi.org/10.15207/JKCS.201 8.9.2.267

Yun, S.Y. and B.J. Choi. 2010. Effect of horticultural therapy on the stress and serum cortisol of demented elders. Korean J. Hortic. Sci. Technol. 28(5):891-894. 